\title{
Influence of Wearing Blue Lenses on Melatonin Production and Performance in Volleyball Players
}

\section{(ㅇ)( $\odot \Theta$}

\author{
Authors

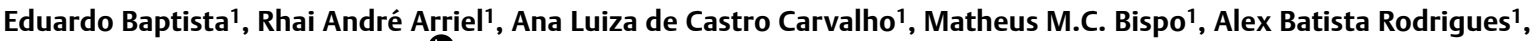 \\ Hiago Souza', Gustavo R. Mota2 ${ }^{\mathbb{D}}$, Moacir Marocolo ${ }^{1}$
}

\section{Affiliations}

1 Institute of Biological Sciences, Department of Physiology, Universidade Federal de Juiz de Fora, Juiz de Fora, Brazil

2 Department of Sport Sciences/Institute of Health Sciences, Federal University of Triangulo Mineiro, UBERABA, Brazil

Key words attention, psychomotor performance, physical functional performance

received 16.08 .2021

revised 03.11 .2021

accepted 05.12 .2021

\section{Bibliography}

Sports Medicine International Open 2022; 6: E1-E8

DOI 10.1055/a-1720-6083

ISSN 2367-1890

(c) 2022. The Author(s).

This is an open access article published by Thieme under the terms of the Creative Commons Attribution-NonDerivative-NonCommercial-License, permitting copying and reproduction so long as the original work is given appropriate credit. Contents may not be used for commecial purposes, or adapted, remixed, transformed or built upon. (https://creativecommons. org/licenses/by-nc-nd/4.0/)

Georg Thieme Verlag KG, Rüdigerstraße 14,

70469 Stuttgart, Germany

\section{Correspondence}

Prof. Moacir Marocolo

Universidade Federal de Juiz de Fora

Institute of Biological Sciences

Department of Physiology

Rua José Lourenço Kelmer s/n

36036-900 Juiz de Fora

Brazil

Tel.: + 55/32/2102 3211, Fax: + 55/32/21023211

isamjf@gmail.com

\begin{abstract}
We analyzed the effects of wearing blue lenses on melatonin level, physical and cognitive performance. Fifteen youth volleyball players ( $15.0 \pm 1.5 \mathrm{yrs}$ ) attended the laboratory on 3 occasions (48-h interval): on the $1^{\text {st }}$ visit they were familiarized with the procedures of the study, and on $2^{\text {nd }}$ and $3^{\text {rd }}$ visits they were submitted to the testing protocol wearing transparent (control) or blue lens glasses in a counterbalanced crossover design. The protocol consisted of $10 \mathrm{~min}$ in "total darkness," 30 min of light stimulation (wearing blue or transparent lenses), followed by an attentional test, and an agility T-test (without wearing the glasses). Samples of saliva (to determine melatonin concentration) were obtained pre- and post-exposure (30 min) to artificial light, wearing the lenses. Sleepiness, alertness, attention, mood, and perceived recovery status and performance variables (reaction time and T-test) were assessed after lens exposure. Melatonin levels did not differ within and between groups (blue lenses, pre: $0.79 \pm 0.73$ and post: $1.19 \pm 1.374 \mathrm{pg} /$ $\mathrm{dl}, \mathrm{p}=0.252$, effect size $(E S)=0.38$; control, pre: $0.97 \pm 1.00$ and post: $0.67 \pm 0.71 \mathrm{pg} / \mathrm{dl}, \mathrm{p}=0.305$, ES $=-0.35$ ). Nonetheless, melatonin differences were significantly correlated with physical sedation for glasses with blue lenses ( $r=-0.526 ; p=0.04)$. No other variables differed $(p>0.05)$ between protocols, including T-test performance $(p=0.07 ; E S=0.41)$. Blue lenses do not influence melatonin levels, cognitive/physical performance, and mood status in amateur youth volleyball players.
\end{abstract}




\section{Introduction}

Biological processes such as cardiac, endocrine, and brain processes have standardized rhythms under the environmental stimulation of the presence (or absence) of light [1]. Vision is a means of receiving light stimuli and maintaining circadian synchronism, as one of the most important senses in humans. Light exposure is the main stimuli for synchronizing circadian rhythms, releasing hormonal alterations, and influencing motor and cognitive tasks and even athletic performance [1].

In this context, melatonin plays a role in the regulation of a variety of physiological processes such as the circadian clock in the suprachiasmatic nucleus, vascular response, reproduction, sleep and cognition [2, 3]. Light exposure to different illumination patterns is a feasible and low-cost tool and could help improve depression and anxiety recovery, alertness state, and performance. The relationship between exposure to light and decreased melatonin secretion has been documented [4], and sports scientists showed that lower levels of melatonin were associated with greater speed in reaction time, an important indicator of the cognitive processes in sports [5-10].

Volleyball is a team sport involving intermittent and unpredictable actions, with intense physical demands interspersed with moments of pause [11]. Volleyball players must have a high cognitive and attention flexibility (broad and selective) for excellent performance [12]. However, competitions often take place at night, when most athletes are past their peak performance period of the day, and exposure to light can lead to a decrease in melatonin levels. A lower melatonin level might decrease the natural loss in reaction time that occurs after long periods of wakefulness [13].

The effect of monochromatic blue can be even greater in suppressing melatonin levels $[14,15]$. However, there is scarce knowledge about the effects of wearing glasses with blue lenses on improving sports performance and pre-activation of the motor cortex of the central nervous system. Any improvement in alertness, and cognitive and physical performance potentially could benefit sports performance (e. g., volleyball) and have a practical application. Thus, the aim of the present study was to analyze whether wearing glasses with blue lenses under an artificial light pattern would influence the melatonin level, physical and cognitive performance of youth volleyball players. Our hypothesis was that wearing blue lens glasses would promote acute suppression of melatonin production (via modulation of the central nervous system), triggering improvements in alertness, cognitive performance, and agility.

\section{Materials and Methods}

\section{Subjects}

Fifteen youth volleyball players participated in this study $(15.1 \pm 1.5$ years; $180.9 \pm 11.5 \mathrm{~cm} ; 76.6 \pm 13.9 \mathrm{~kg}$, body mass index $23.4 \pm 3.9 \mathrm{~kg} /$ $\mathrm{m}^{2}$ ). Their usual awakening time was between $6: 30$ am and 10:40 am. The research project was approved by the local Ethics and Research Committee (n. 68569417.5.0000.5147). The volunteers and their parents signed a free and informed consent form before the beginning of the experiments. The following inclusion criteria were used: 1) male gender, 2) participant in competitive youth volleyball team, 3) abstained from exercise within 24 hours prior to testing, and 4) having a chronotype between 1 (moderately morning) and 5 (moderately evening). Since our goal was to avoid a predominantly morning or evening sample, we believed that the above chronotype description was an inclusion criterion.

Exclusion criteria were: 1 ) having a history of injuries that compromised the tests; 2 ) having used dietary supplements or medications that could affect performance for at least 2 weeks before testing; 3 ) present health problems that prevented the procedures from being performed; 4) having any visual impairment related to the distinction and visualization of colors; and 5) having changed time zones in the week before the tests.

\section{Experimental design}

The players attended the laboratory on 3 occasions with a 48-h interval in between. On the first visit, they were characterized by age, body mass, height, and body mass index (weight/height ${ }^{2}$ ), and reported their time of experience in volleyball. The athletes also received the Pittsburgh Sleep Quality Index (PSQI) [16] and the Morningness-Eveningness Questionnaire [17] to be delivered completed on test days. They were then asked to abstain from intense physical activity and the use of alcoholic beverages and/or stimulants 24 hours prior to the tests, and to maintain their usual bedtime and waking time the day before the tests and on test days. Finally, the athletes were familiarized with the procedures of the experiment.

On the other two visits, the glasses (blue or transparent) were randomly selected for the participants, who performed the experimental procedures in a counterbalanced manner. Initially, the athletes were sent to the laboratory where they remained seated with their arms and head supported, avoiding any kind of sudden movement. This position was maintained for a period of 10 minutes in "total darkness" with their eyes totally blindfolded by a mask and with all the lamps out, with 0 lux, verified through the lux meter (Victor 1010 A Auto Digital Lux Meter). The period of "total darkness" was followed by the first collection of saliva, which was labeled and stored in an ultra-freezer at $-80^{\circ} \mathrm{C}$. Soon after, the individuals were submitted to light stimulation. The light stimulus was modified by wearing the blue or transparent lenses (according to a drawing). The use of lenses was carried out only during the period in which the subjects remained in the condition of light stimulation. At the end of this period, each participant was asked, "How do you feel right now?". The athletes also checked the Karolinska Sleepiness Scale [7, 18, 19], their current state of alertness or drowsiness, and the Visual Analogue Mood Scale [7, 20]. Upon completing these procedures, a salivary melatonin sample was again collected, labeled, and stored in an ultra-freezer. After the second collection of the saliva sample, the athletes were taken to an annex of the physiology laboratory for the Attentional Network Test [21]. Thereafter, they were taken a little further to the yard for the T-test. $>$ Fig. 1 shows the experimental design of the study.

All data relating to the attentional network test and the T-test were noted on a form and allocated to a file within the physiology laboratory in conjunction with the Sleep Quality MorningnessEveningness Questionnaire, Visual Analogue Mood Scale, Karolinska Sleepiness Scale, and subjective recovery scale. 


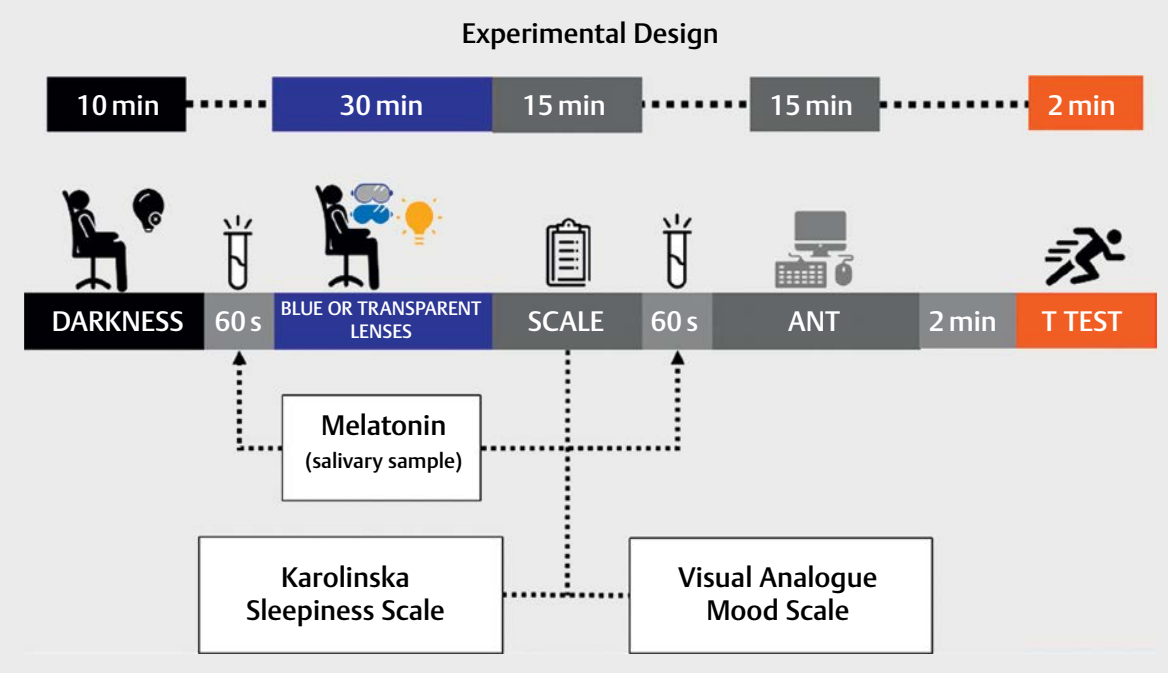

- Fig. 1 Experimental Design of the Study.

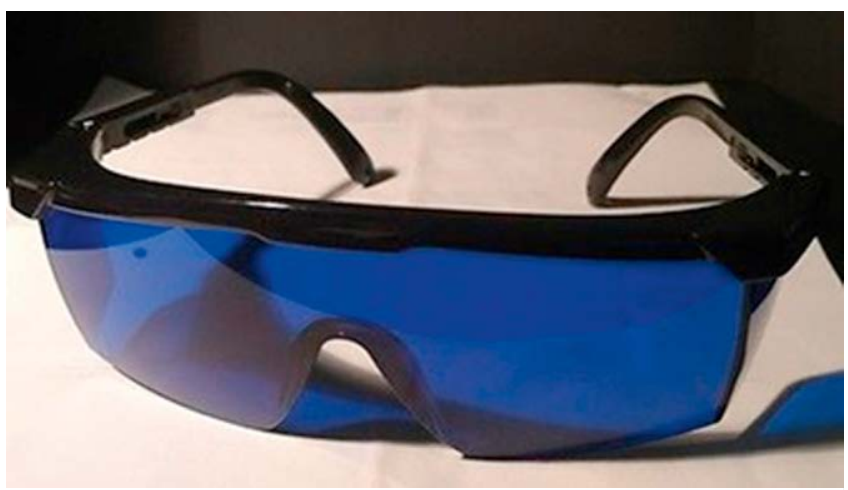

Fig. 2 Blue Safety Glasses.

\section{The environment}

The ambient lighting was provided by 12 fluorescent lamps of the Philips TLD 32 W/840-NG Super 84 Eco Master tube, each with a luminous flux (lumens - Im) of 2700 lumens, a temperature of 4,100 kelvin, a wavelength of approximately 550 nanometers, a power of 32 watts, with a total size of 121 centimeters. They were positioned in pairs horizontally by means of six TBS050 luminaires (Embed), with a general diffuse lighting characteristic, and a distance of 2.50 meters from the light source to the ground. The average lux of the laboratory was calculated using the formula: Luminous flux (lumens)/ illuminated surface area (meters $\left.{ }^{2}\right)$, calculated as $(2,700 \times 12) / 39.4$ $\cong 822$ fluxes, complying with ICS 91.160 .10 . The temperature $\left(22 \pm 1.0^{\circ} \mathrm{C}\right)$ and relative humidity $(66 \pm 2.0 \%)$ of the environment were controlled.

\section{Blue monochrome color lenses}

The lenses ( $\triangleright$ Fig. 2 ) are composed of yellow, green, and red spectrum protection lenses (Blue Safety Glasses $492 \mathrm{~nm}-770 \mathrm{~nm}$ ) in a blue monochrome color and transparent lenses (without protection). > Fig. 2 shows the blue lens goggles used.

\section{Morningness-Eveningness Questionnaire}

To identify the chronotype, the Horne and Ostberg's MorningnessEveningness Questionnaire [17] was used, translated into Portuguese by Benedito-Silva et al. [22]. This is a questionnaire of selfassessment that categorizes a person based on their preference for performing routine activities in the morning or evening. The result is a numerical value that varies between 16 and 86 points, classifying the individual in 5 (five) different types: extreme afternoon (16 to 30 points), moderately afternoon ( 31 to 41 points), indifferent (42 to 58 points), moderately morning (59 to 69 points) and extreme morning (70 to 86 points).

\section{Sleep Quality Index - PSQI}

The PSQI [16] translated into Portuguese [23] was applied to assess the subjects' sleep quality for the last month. The questionnaire consists of 19 self-administered questions and 5 questions answered by a roommate (only used for clinical evaluations). Thus, the 19 questions are grouped into 7 components, distributed on a scale of 0 to 3 . These PSQI components are divided into subjective "sleep quality," "sleep latency," "sleep duration," "habitual sleep efficiency," "sleep disorders," "use of sedative medications," and "daytime dysfunction." Therefore, the scores for these components are added to produce a global score, which ranges from 0 to 21 , with the higher the score, the worse the quality of sleep. A PSQI greater than five indicates that the individual is experiencing great difficulties in at least 2 components or moderate difficulties in more than 3 components.

\section{Illuminance measurement}

Illuminance is defined as the luminous flux, the amount of light that reaches a certain point. The unit of measure of illuminance is expressed in lux and was measured using the Victor 1010 A Auto Digital Lux Meter. According to ICS 91.160.10, to correctly use the lux meter, the evaluator must maintain the device at an illuminance similar to that of the environment for 5 to 10 minutes for stabilization, 
perform measurements on the work plane, and maintain a minimum distance of 2 meters from the lux meter cell so that the luminous flux is not influenced by the person taking the measurement. All measurements were performed at the participant's eye level.

\section{Salivary melatonin measurements}

All pre-test samples were collected between 18:00h-18:30 h, the period in which the beginning of the melatonin synthesis threshold in low light begins to increase significantly. All samples were collected in a tube (salivary kit collection $1 \mathrm{ml}$ - melatonin), with all individuals seated, with at least 0.5 milliliters of saliva collected. The melatonin analysis was performed using the Automated Enzyme Immunoassay analysis kit (IBL International, Hamburg, Germany). The minimum detectable dosage of melatonin (analytical sensitivity) was determined to be $0.30 \mathrm{pg} / \mathrm{ml}$. Salivary samples were collected following previous recommendations [24, 25].

The participant stimulated the production of saliva and deposited it in the bottle until reaching the equivalent of at least $0.5 \mathrm{ml}$. Immediately after salivary collection, the vial was identified with the athlete's name and labeled pre or post and blue or transparent lenses. Duly identified, it was deposited in a polystyrene box in an upright position and stored in an ultra-freezer at a temperature of $-80^{\circ} \mathrm{C}$ for further analysis.

\section{Karolinska Sleepiness Scale}

In order to check the subject's state of alert and sleepiness, the Karolinska Sleepiness Scale [18] was applied. The scale consists of 9 points, where each item features a characteristic: 1 = very alert, 3 = alert, 5 = neither alert nor sleepy, 7 = sleepy, 9 = very sleepy. After the light exposure, the subjects were asked to visualize the scale to verify their real state at the moment.

\section{Visual Analogue Mood Scale}

The Visual Analogue Mood Scale [26], translated to Portuguese [20], consists of 16 items. Each of them was represented by a straight line of 100 millimeters connecting two opposite feelings. Four intuitive factors were combined into these items: anxiety, physical sedation, mental sedation, and other feelings. Before applying the scale, previous training was carried out, featuring oral instructions and practical examples about the scale. Furthermore, it is important that oral instructions emphasize that both ends of the line should be considered the maximum the subject can feel with respect to that item and the center is equivalent to its usual state. Hence, the subject filled each item by crossing the line that links the two opposite characteristics in all sixteen items on the scale.

\section{Attentional Network Test}

The Attentional Network Test (ANT) developed by Fan et al. [21] includes a computer test featuring "opposed" tasks and their respective answers verified through the reaction time (RT) in milliseconds and percentage of correct answers. In addition, the ANT requires the subject to determine in a set of five arrows whether the central object is pointing left or right. As a reference, the arrows appear above or below central point in the screen, accompanied or not by arrows indicating opposite (incongruent) or equal (congruent) sides. Thus, ANT's efficiency is assessed by measuring how the RT is influenced through the warning tips, spatial tips, and congruence of the arrows. Moreover, executive functions such as alertness and guidance are also assessed through the ANT. The session consists of a practical part that lasts for 2 minutes and contains a block of 24 models, presenting the right and wrong answers during the subject's practice. After that, the experimental model is generated, showing a total of 3 blocks of 5 minutes, each block presents 96 models randomly, without any feedback response. Therefore, the ANT test is used to test refined motor skills, with a high demand for precise movement made by small muscle groups, which generally involves high levels of coordination between the eyes and hands [13].

\section{T-test}

An adapted version of the T-test [27] was used with its measurements reduced. This version of the test consists of a frontal and posterior move of 5 (five meters), and two opposed lateral moves of 2.5 (two meters and fifty centimeters).

The test site was previously marked with orange paint spray for positioning the " $T$ " shaped cones. Four cones $24 \mathrm{~cm}$ high were placed in each marked space and named A, B, C and D. The athlete had to stay just behind cone $A$ and wait for the call to start that was given from the countdown of 3 (three) seconds. The athlete quickly moved forward to cone $B$, then moved laterally to cone $C$ and laterally to cone D. Finally, the athlete moved laterally to cone $B$ and later to the beginning at cone $A$. When the subject reached the cones $B, C$, and $D$, a squat movement was performed, followed by touching the fingertips to the respective cones. The total test time (in seconds) was recorded by two evaluators using two Samsung Galaxy 56 stopwatches when the athlete reached cone A, signaling the end of the test. Trials with more than $3 \%$ difference were not considered.

\section{Subjective Recovery Perception Scale}

To verify the athletes' current recovery level, the Subjective Recovery Perception Scale (SRP) [28] was utilized. The SRP has reference values from 0 to 10 in the extremes, meaning "extremely tired" and "very well recovered," respectively.

\section{Statistical analysis}

The normality of the data was verified by the Shapiro-Wilk test. For melatonin response, two-way analysis of variance (ANOVA) repeated measurements followed by Bonferroni's post hoc test was conducted to assess the interaction between time and intervention. For the other variables, the Student's paired t-test or Wilcoxon test was performed to verify differences between interventions. In addition, to verify correlation between melatonin differences and cognitive and performance parameters, a Spearman's test was performed. IBM SPSS statistical software (Version 20; IBM Corp., Armonk, NY, USA) was used to perform data analyses. The level of significance adopted was $p<0.05$. Cohen's $d$ effect size (ES) were calculated and magnitude was classified as: $<0.2=$ trivial, $0.2-$ $0.6=$ small, $0.6-1.2=$ moderate, $1.2-2.0=$ large, and $>2.0=$ very large [29]. 


\section{Results}

Using a post-hoc statistical power test with 15 participants, a power of 0.76 was reached [ $G$ * Power Software (Dusseldorf, Germany); statistical test = ANOVA: repeated measures, within-between interaction; $\alpha=0.05$; $E S=0.37$; number of groups $=2$; and number of measures $=2$ ]. All volleyball players were exposed to the same illuminance level (blue lenses, 352.4 \pm 35.9 lux; transparent lenses, $349.2 \pm 35.1$ lux; $p=0.834, E S=0.09)$.

There was no time effect $[F(1,14)=0.035, p=0.854)$ or interaction between time and intervention $[F(1,14)=3.576, p=0.08]$ for melatonin. In both conditions [(blue lens, pre: $0.79 \pm 0.73$ to post: $1.19 \pm 1.37(\mathrm{pg} / \mathrm{dL}), \mathrm{p}=0.252$, ES $=0.38$; colorless lens, pre $0.97 \pm 1.00$ to post $0.67 \pm 0.71(\mathrm{pg} / \mathrm{dL}), \mathrm{p}=0.305$, ES $=-0.35$ ], post hoc analysis showed that melatonin did not change within and between groups ( $\vee$ Fig. 3 ).

There were no changes between blue and transparent lenses on the Karolinska Sleepiness Scale (Blue, 4.2 $\pm 1.7 \mathrm{KSS}$; colorless, $4.9 \pm 1.2 \mathrm{KSS} ; \mathrm{p}=0.148 ; E S=-0.48)$, although a small ES was found, and the Visual Analogue Mood Scale ( $\triangleright$ Table 1).

Concerning ANT, there was no significant difference in the number of correct answers ( $p=0.308)$ between blue and transparent lenses. The same was observed to time reaction $(p=0.698)$ and Ttest performance $(p=0.066)$. However, as for T-test performance, a small ES was found. These results are displayed in > Fig. 4.

A negative significant correlation was observed between melatonin differences and physical sedation for glasses with blue lenses. No other significant correlations were found ( $\triangleright$ Table 2 ).

\section{Discussion}

Although a previous investigation evaluated the acute effects of wearing colored-lens glasses on exercise performance and testosterone concentration [30], in this study we tested the effects of wearing blue lenses under artificial light conditions in melatonin responses, and physical and cognitive performance. Overall, we found no significant differences when assessing salivary melatonin, alertness, mood, and performance variables (reaction time and Ttest).

In contrast with previous investigations [6, 7, 31-33], light exposure in our study did not reduce salivary melatonin level. However, these studies used a longer period than 30 minutes, suggesting that the time of exposure to light may influence the outcome.

Some studies have shown a correlation between subjective alertness and measures of cognitive performance [34, 35]. In light of these results, Zhou et al. [36] proposes that the subjective alertness may not reflect an improvement in cognitive performance and vice versa, and that a reduction in alertness does not always reflect some impairment in cognitive performance tasks. The present study does not present a significant difference in the alertness level, nor did it demonstrate improved cognitive performance from the use of blue lenses, given the lighting condition. However, other studies demonstrated that exposure to light caused changes in both objective and subjective measures of alertness and improvements in cognitive performance [7, 37-39].

An important aspect of our results is that a complex psychomotor test was used to analyze the objective measure of cognition. No relevant changes were observed in the reaction time with the use

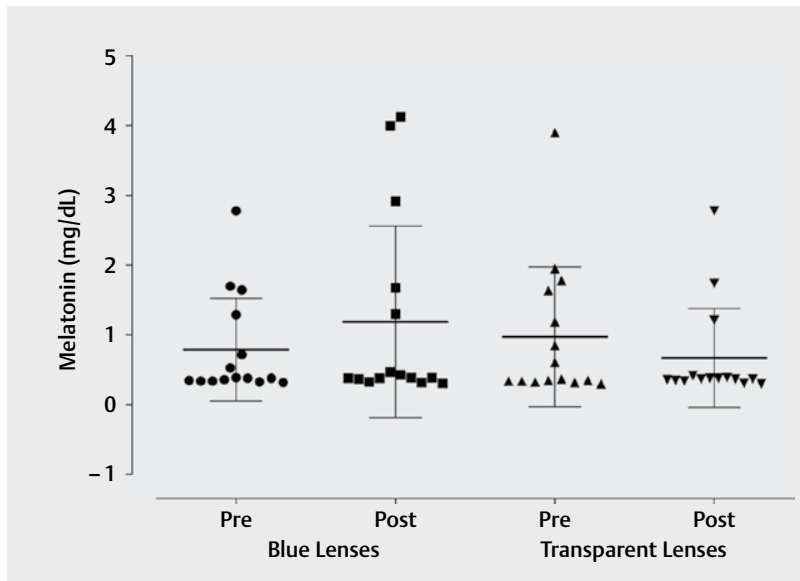

- Fig. 3 Melatonin responses before and after exposure of the blue and transparent lenses. Data are expressed as individual values \pm SD.

- Table 1 Visual Analogue Mood Scale: results between blue and transparent lenses.

\begin{tabular}{|l|l|l|l|r|}
\hline & Blue lens & $\begin{array}{l}\text { Transpar- } \\
\text { ent lens }\end{array}$ & $\mathbf{P}_{\text {value }}$ & ES \\
\hline Anxiety $(\mathrm{mm})$ & $177.0 \pm 30.0$ & $168.0 \pm 19.0$ & 0.589 & 0.17 \\
\hline Physical sedation (mm) & $315.0 \pm 80.0$ & $327.0 \pm 66.0$ & 0.532 & 0.05 \\
\hline Mental sedation (mm) & $107.0 \pm 17.0$ & $110.0 \pm 34.0$ & 0.875 & 0.20 \\
\hline Other feelings (mm) & $165.0 \pm 40.0$ & $177.0 \pm 47.0$ & 0.570 & -0.17 \\
\hline \multicolumn{4}{|l}{ Median \pm interquartile range; effect size, ES. } \\
\hline
\end{tabular}

of lenses with filters and without filters. These results may be due to the non-specificity of the test. The reaction time reflects the nature and duration of the cognitive processes, intervening in successive stages of information processing, between presentation of the stimulus and the response [40]. This proves to be of fundamental importance for volleyball players because, suddenly, there is a need for wide attention to other situations that require selective attention before analyzing the specific stimulus and selecting the appropriate action.

During this experiment, the illuminance pattern was kept constant, using 12 fluorescent lamps with a color temperature of 4,100 kelvin, generating a total lux measurement of $\sim 822$ lux, and at eye level in the vertical plane, a measurement of $~ 352$ lux. According to Cajochen et al. [41], exposure to a lighting pattern of around 90 to 180 lux is sufficient to promote changes in objective and subjective measures of alertness as well as melatonin suppression. It is important to note that the research by Cajochen et al. [41] used the Constant Routine method, in which all individuals were systematically controlled in relation to the pattern of sleep, awakening, food and fluid intake, which was not possible with the same technique in our work.

Regarding the lack of positive findings under the effect of alertness/drowsiness, it is important to mention the work of Souman et al. [42], who carried out a systematic review on the acute effects of the state of alertness upon exposure to light in a review of publications of the last 26 years (1990-2016). It was found that most studies reported significant differences in subjective alertness; 


\section{a}

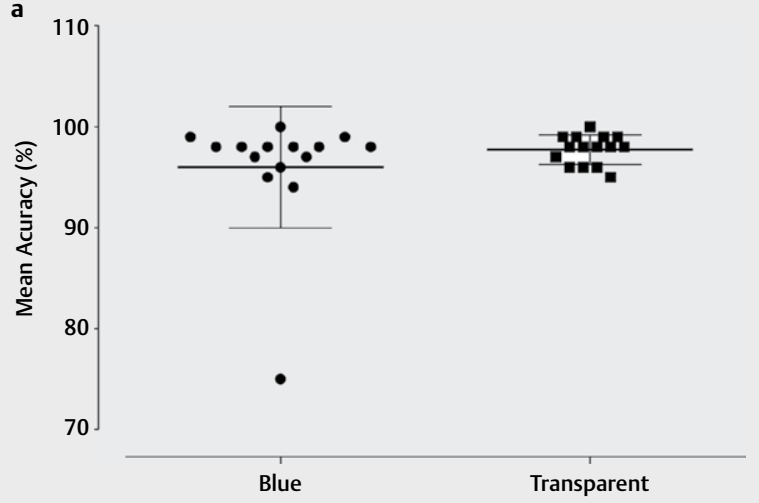

b
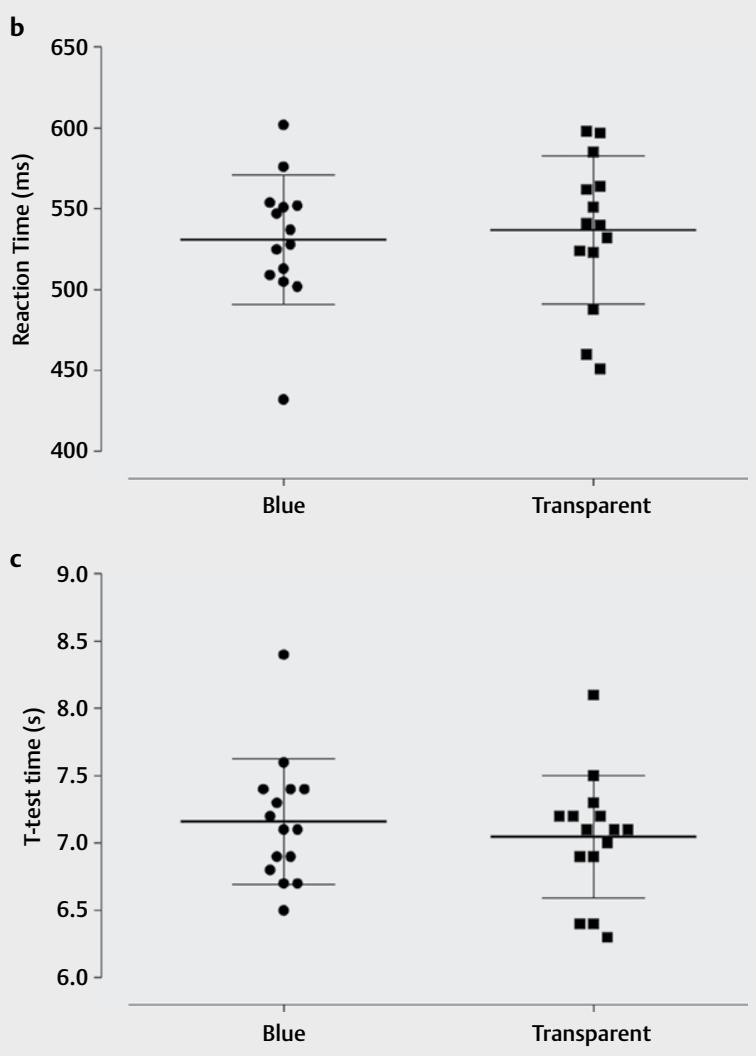

Fig. 4 a, Accuracy results $(p=0.308, E S=-0.47)$; $b$, Reaction time $(p=0.698, E S=-0.14) ; c$, T-test $(P=0.066 ; E S=0.41)$. Data are expressed as individual values \pm SD.

however 17 of 45 studies (38\%) were unable to find a significant effect. This can be justified by a set of factors such as chronotyping, circadian phase, history of previous light, and genetic factors. We were able to control only the chronotypology of the participants, who were classified as indifferent chronotypology (47.8 \pm 9.9 ), and the circadian phase, with all evaluations performed in the same night period after 18:00, when the melatonin production threshold was reached in low light [24].

Regarding the state of mood, it was expected that through the use of lenses with filters, the subjective state of alertness would be changed, and consequently the state of mental sedation (alert and
- Table 2 Correlation between melatonin differences and alertness, cognitive and performance parameters for glasses with blue and transparent lenses.

\begin{tabular}{|l|l|l|}
\hline & $\begin{array}{l}\text { Glasses with blue } \\
\text { lenses }\end{array}$ & $\begin{array}{l}\text { Glasses with } \\
\text { transparent lenses }\end{array}$ \\
\hline & $\begin{array}{l}\text { Melatonin } \\
\text { differences }\end{array}$ & $\begin{array}{l}\text { Melatonin } \\
\text { differences }\end{array}$ \\
\hline Iluminance level & -0.432 & -0.179 \\
\hline KSS & 0.002 & 0.002 \\
\hline Anxiety & 0.434 & 0.083 \\
\hline Physical sedation & $-0.526^{*}$ & -0.034 \\
\hline Mental sedation & -0.144 & 0.296 \\
\hline Other feelings & 0.066 & -0.091 \\
\hline ANT & 0.378 & 0.381 \\
\hline Reaction time & 0.020 & 0.168 \\
\hline T-test & -0.429 & -0.076 \\
\hline $\begin{array}{l}\text { KSS, Karolinska Sleepiness Scale; ANT, Attentional Networks Test; } \\
{ }^{*} \mathrm{p}=0.044\end{array}$ & \\
\hline
\end{tabular}

attentive). We ascertained only an ES of 0.2 for mental sedation. Leichtfried et al. [43], unlike us, observed changes in the state of subjective mood when healthy individuals were exposed to an illumination of 6,500 kelvin in the morning. It is important to note that this color temperature pattern has a band of short length (blue spectrum), unlike the color temperature of 4,100 kelvin. This is of fundamental importance because non-visual reception is more sensitive to short wavelength bands compared to cones and rods, which are more sensitive to medium-length waves and may have influenced subjective mood. The authors also performed stimulation in the daytime, as this subjective measure was more conducive to changes in the morning.

Our objective was to observe whether stimulation during the night would modify biological circadian changes (acute melatonin suppression and subjective alertness) in conjunction with psychometric changes (subjective mood), especially in relation to mental sedation; however this it did not occur in our study. On the other hand, Plitnick et al. [44] demonstrated that night exposure to lighting with short (blue) or long (red) waves caused positive changes in the subjective measures of alertness and mood, regardless of the decrease in salivary melatonin levels. In our study, no significant correlation was found between melatonin differences and mental sedation and KSS for both glasses with blue and transparent lenses. This can demonstrate a dissociation of patterns of changes in circadian biological measures and psychological status. However, a significant negative correlation was found between melatonin differences and physical sedation.

One of the limitations of our work is related to records of sleep quality. No actigraphy measures were used to record normal sleep periods or periods of insomnia during the study. The amount and time of exposure to light is another factor that may have interfered with the results. In a clinical trial, an interesting result was identified that may point to improvements in the research methodology on the effects of exposure to light and suppression of melatonin. It has been found that exposure to blue light can increase subjective alertness, but did not influence objective alertness [45]. An impor- 
tant aspect of these data is that Hanifin et al. [45] and other authors used more than 30 minutes of exposure to light [6, 7, 33]. Finally, although we measured the T-test time with a stopwatch, the considered difference measurement error between evaluators was no more than $3 \%$.

\section{Conclusion}

Exposure to an equivalent lighting pattern using blue protection or transparent lenses (492 nm-770 nm), under the same exposure time at night, did not cause significant changes in the salivary melatonin profile, in the cognitive patterns, physical performance, and the mood state of youth volleyball players.

\section{Acknowledgements}

This research was supported by the Federal University of Juiz de Fora.

\section{Conflict of Interest}

The authors declare that they have no conflict of interest.

\section{References}

[1] van Bommel W, van den Beld G. Lighting for work: a review of visual and biological effects. Light Res Technol 2004; 36: 255-266. doi:10.11 91/1365782804li122oa

[2] Hardeland R, Cardinali DP, Srinivasan V et al. Melatonin - a pleiotropic, orchestrating regulator molecule. Prog Neurobiol 2011; 93: 350-384. doi:10.1016/j.pneurobio.2010.12.004

[3] Pandi-Perumal SR, Trakht I, Srinivasan V et al. Physiological effects of melatonin: role of melatonin receptors and signal transduction pathways. Prog Neurobiol 2008; 85: 335-353. doi:10.1016/j. pneurobio.2008.04.001

[4] Lewy AJ, Wehr TA, Goodwin FK et al. Light suppresses melatonin secretion in humans. Science 1980; 210: 1267-1269. doi:10.1126/ science. 7434030

[5] Beaven CM, Ekström J. A comparison of blue light and caffeine effects on cognitive function and alertness in humans. PLoS One 2013; 8: e76707. doi:10.1371/journal.pone.0076707

[6] Cajochen C, Münch M, Kobialka S et al. High sensitivity of human melatonin, alertness, thermoregulation, and heart rate to short wavelength light. J Clin Endocrinol Metab 2005; 90: 1311-1316. doi:10.1210/jc.2004-0957

[7] Chellappa SL, Steiner R, Blattner P et al. Non-visual effects of light on melatonin, alertness and cognitive performance: can blue-enriched light keep us alert? PLoS One 2011; 6: e16429. doi:10.1371/journal. pone. 0016429

[8] Papamichael C, Skene DJ, Revell VL. Human nonvisual responses to simultaneous presentation of blue and red monochromatic light. J Biol Rhythms 2012; 27: 70-78. doi:10.1177/0748730411431447

[9] Viola AU, James LM, Schlangen LJM et al. Blue-enriched white light in the workplace improves self-reported alertness, performance and sleep quality. Scand J Work Environ Health 2008; 34: 297-306. doi:10.5271/sjweh.1268
[10] Voss MW, Kramer AF, Basak C et al. Are expert athletes 'expert' in the cognitive laboratory? A meta-analytic review of cognition and sport expertise. Appl Cogn Psychol 2010; 24: 812-826. doi:10.1002/ acp. 1588

[11] Sheppard JM, Gabbett T], Stanganelli L-CR. An analysis of playing positions in elite men's volleyball: considerations for competition demands and physiologic characteristics. J Strength Cond Res 2009; 23: 1858-1866. doi:10.1519/JSC.0b013e3181b45c6a

[12] Posner MI. Orienting of attention. Q J Exp Psychol 1980; 32: 3-25. doi:10.1080/00335558008248231

[13] Knufinke M, Nieuwenhuys A, Maase K et al. Effects of natural between-days variation in sleep on elite athletes' psychomotor vigilance and sport-specific measures of performance. J Sports Sci Med 2018; 17: 515-524

[14] Brainard GC, Hanifin JP, Greeson JM et al. Action spectrum for melatonin regulation in humans: evidence for a novel circadian photoreceptor. J Neurosci 2001; 21: 6405-6412

[15] Thapan K, Arendt J, Skene DJ. An action spectrum for melatonin suppression: evidence for a novel non-rod, non-cone photoreceptor system in humans. J Physiol 2001; 535: 261-267. doi:10.1111/j.1469-7793.2001.t01-1-00261.x

[16] Buysse DJ, Reynolds CF, Monk TH et al. The Pittsburgh Sleep Quality Index: a new instrument for psychiatric practice and research. Psychiatry Res 1989; 28: 193-213. doi:10.1016/0165-1781(89)90047-4

[17] Horne JA, Ostberg O. A self-assessment questionnaire to determine morningness-eveningness in human circadian rhythms. Int J Chronobiol 1976; 4: 97-110

[18] Akerstedt T, Gillberg M. Subjective and objective sleepiness in the active individual. Int J Neurosci 1990; 52: 29-37. doi:10.3109/00207459008994241

[19] Sahin L, Figueiro MG. Alerting effects of short-wavelength (blue) and long-wavelength (red) lights in the afternoon. Physiol Behav 2013; 116-117: 1-7. doi:10.1016/j.physbeh.2013.03.014

[20] Zuardi AW, Karniol IG. Estudo transcultural de uma escala de auto-avaliacao para estados subjetivos. J bras psiquiatr 1981; 30: 403-406

[21] Fan J, McCandliss BD, Sommer T et al. Testing the efficiency and independence of attentional networks. J Cogn Neurosci 2002; 14 : 340-347. doi:10.1162/089892902317361886

[22] Benedito-Silva AA, Menna-Barreto L, Marques $\mathrm{N}$ et al. A selfassessment questionnaire for the determination of morningnesseveningness types in Brazil. Prog Clin Biol Res 1990; 341B: 89-98

[23] Bertolazi AN, Fagondes SC, Hoff LS et al. Validation of the Brazilian Portuguese version of the Pittsburgh Sleep Quality Index. Sleep Med 2011; 12: 70-75. doi:10.1016/j.sleep.2010.04.020

[24] Benloucif S, Burgess HJ, Klerman EB et al. Measuring melatonin in humans. J Clin Sleep Med 2008; 04: 66-69. doi:10.5664/jcsm.27083

[25] Rahman SA St, Hilaire MA, Gronfier $C$ et al. Functional decoupling of melatonin suppression and circadian phase resetting in humans. J Physiol 2018; 596: 2147-2157. doi:10.1113/JP275501

[26] Norris $\mathrm{H}$. The action of sedatives on brain stem oculomotor systems in man. Neuropharmacology 1971; 10: 181-191. doi:10.1016/00283908(71)90039-6

[27] Sassi RH, Dardouri W, Yahmed MH et al. Relative and absolute reliability of a modified agility $\mathrm{T}$-test and its relationship with vertical jump and straight sprint. J Strength Cond Res 2009; 23: 1644-1651. doi:10.1519/JSC.0b013e3181b425d2

[28] Laurent CM, Green JM, Bishop PA et al. A practical approach to monitoring recovery: development of a perceived recovery status scale. J Strength Cond Res 2011; 25: 620-628. doi:10.1519/ JSC.0b013e3181c69ec6 
[29] Hopkins WG, Marshall SW, Batterham AM et al. Progressive statistics for studies in sports medicine and exercise science. Med Sci Sports Exerc 2009; 41: 3-13. doi:10.1249/MSS.0b013e31818cb278

[30] Londe AM, Marocolo M, Marocolo IC et al. Wearing colored glasses can influence exercise performance and testosterone concentration? Sports Med Int Open 2018; 2: E46-E51. doi:10.1055/a-0601-7250

[31] Appleman K, Figueiro MG, Rea MS. Controlling light-dark exposure patterns rather than sleep schedules determines circadian phase. Sleep Med 2013; 14: 456-461. doi:10.1016/j.sleep.2012.12.011

[32] Higuchi S, Fukuda T, Kozaki T et al. Effectiveness of a red-visor cap for preventing light-induced melatonin suppression during simulated night work. J Physiol Anthropol 2011; 30: 251-258. doi:10.2114/ jpa2.30.251

[33] Lockley SW, Evans EE, Scheer FAJL et al. Short-wavelength sensitivity for the direct effects of light on alertness, vigilance, and the waking electroencephalogram in humans. Sleep 2006; 29: 161-168

[34] Dorrian J, Lamond N, Holmes AL et al. The ability to self-monitor performance during a week of simulated night shifts. Sleep 2003; 26 : 871-877. doi:10.1093/sleep/26.7.871

[35] Wright HR, Lack LC, Kennaway D]. Differential effects of light wavelength in phase advancing the melatonin rhythm. J Pineal Res 2004; 36: 140-144. doi:10.1046/j.1600-079x.2003.00108.x

[36] Zhou X, Ferguson SA, Matthews RW et al. Mismatch between subjective alertness and objective performance under sleep restriction is greatest during the biological night. J Sleep Res 2012; 21: 40-49. doi:10.1111/j.1365-2869.2011.00924.x

[37] Askaripoor T, Motamedzadeh M, Golmohammadi R et al. Non-image forming effects of light on brainwaves, autonomic nervous activity, fatigue, and performance. J Circadian Rhythms 2018; 16: 9. doi:10.5334/jcr.167
[38] Chang A-M, FAJL Scheer, Czeisler CA et al. Direct effects of light on alertness, vigilance, and the waking electroencephalogram in humans depend on prior light history. Sleep 2013; 36: 1239-1246. doi:10.5665/sleep.2894

[39] Figueiro MG, Sahin L, Wood B et al. Light at night and measures of alertness and performance: implications for shift workers. Biol Res Nurs 2016; 18: 90-100. doi:10.1177/1099800415572873

[40] Fontani G, Maffei D, Cameli S et al. Reactivity and event-related potentials during attentional tests in athletes. Eur J Appl Physiol Occup Physiol 1999; 80: 308-317. doi:10.1007/s004210050597

[41] Cajochen C, Zeitzer JM, Czeisler CA et al. Dose-response relationship for light intensity and ocular and electroencephalographic correlates of human alertness. Behav Brain Res 2000; 115: 75-83. doi:10.1016/ s0166-4328(00)00236-9

[42] Souman JL, Tinga AM, Te Pas SF et al. Acute alerting effects of light: a systematic literature review. Behav Brain Res 2018; 337: 228-239. doi:10.1016/j.bbr.2017.09.016

[43] Leichtfried V, Mair-Raggautz M, Schaeffer V et al. Intense illumination in the morning hours improved mood and alertness but not mental performance. Appl Ergon 2015; 46 Pt A: 54-59. doi:10.1016/j. apergo.2014.07.001

[44] Plitnick B, Figueiro M, Wood B et al. The effects of red and blue light on alertness and mood at night. Ligh Res Technol 2010; 42: 449-458. doi: $10.1177 / 1477153509360887$

[45] Hanifin JP, Lockley SW, Cecil K et al. Randomized trial of polychromatic blue-enriched light for circadian phase shifting, melatonin suppression, and alerting responses. Physiol Behav 2019; 198: 57-66. doi:10.1016/j.physbeh.2018.10.004 